Original Research Article

\title{
Evaluation of prescribing patterns of medical practitioners in the state of Goa, India
}

\author{
Greeshma Upendra*, Sushama A. Bhounsule
}

Department of Pharmacology, Goa Medical College and Hospital, Bambolim, Goa, India

Received: 30 June 2017

Accepted: 24 July 2017

\section{*Correspondence to:}

Dr. Greeshma Upendra,

Email: greeshma0292@

gmail.com

Copyright: (C) the author(s), publisher and licensee Medip Academy. This is an openaccess article distributed under the terms of the Creative Commons Attribution NonCommercial License, which permits unrestricted noncommercial use, distribution, and reproduction in any medium, provided the original work is properly cited

\begin{abstract}
Background: According to WHO, worldwide more than $50 \%$ of all medicines are prescribed, dispensed, or sold inappropriately, while $50 \%$ of patients fail to take them correctly. Evaluating the prescribing patterns of the medical practitioners will throw light on the common types of irrational practices such as inappropriate use of antimicrobials, polypharmacy, over-use of injections, failure to prescribe according to clinical guidelines.

Methods: 600 prescriptions prescribed by medical practitioners from March to April 2016 were analyzed using WHO prescribing indicators.

Results: Out of the 1900 drugs prescribed, average number of drugs per prescription was 3.17. Total number of drugs prescribed by generic name was 11 $(0.58 \%)$. An antibiotic was prescribed in 119 patients $(19.83 \%)$. An injection was prescribed in 23 patients $(3.8 \%) .567$ drugs prescribed were from the essential drug list of India (29.8\%).

Conclusions: Polypharmacy increases the risk of drug interactions, treatment cost, decreases the patient's compliance. Prescribing medicines by generic name avoids the confusion. By adhering to the national essential list of medicine, drugs will be available to the patients at all times and be cheaper.
\end{abstract}

Keywords: National list of essential medicine, Generic name, Prescribing pattern, Prescribing indicators, Polypharmacy, Rational drug use

\section{INTRODUCTION}

WHO has defined the rational use of medicine as, "patients receiving medications appropriate to their clinical needs, in doses that meet their own individual requirements, for an adequate period of time, and at the lowest cost to them and their community". ${ }^{1}$ Unfortunately, in clinical practice, all the above criteria are not always adhered to. WHO has made an alarming statement that worldwide more than $50 \%$ of all medicines are prescribed, dispensed, or sold inappropriately, while $50 \%$ of patients fail to take them correctly. ${ }^{2}$

Some of the irrational practices include polypharmacy, self-medication, inappropriate or inadequate use of antimicrobials, over-use of injections, failure to prescribe in accordance with clinical guidelines. ${ }^{2}$ This leads to antimicrobial resistance, adverse drug reactions, poor patient compliance, increased health care expenditure borne by the patient as well as the government. ${ }^{3}$

In order to combat irrational use of medicines, it is vital to assess the prescribing practices adopted by physicians. World Health Organization (WHO) in collaboration with the International Network of Rational Use of Drugs (INRUD) have developed a set of prescribing indicators to measure the performance of healthcare providers in numerous crucial aspects related to appropriate use of drug.

The aim of this study was to create a baseline data on the drug prescribing patterns of medical practitioners in the 
state of Goa and evaluate its rationality using WHO prescribing indicators.

\section{METHODS}

\section{Study area and period}

This study was carried out in various pharmacies in the state of Goa from March to April 2016.

\section{Sample size and study design}

This was a quantitative and cross sectional study. Photographs of 600 prescriptions prescribed by medical practitioners were taken randomly, to minimize bias. For a cross sectional study to evaluate prescribing practices, a minimum sample size of 600 is required, with a greater number if possible. ${ }^{4}$ Legible prescriptions written by medical practitioners (MBBS, MD, MS, BDS, MDS) were included in this study. Prescriptions belonging to pediatric age groups and those prescribed by super specialists were excluded.

\section{Data analysis}

All data were first analyzed manually and then using Microsoft Excel 2010. Descriptive statistics were utilized. The ideal values for the prescribing indicators were adopted from previous studies. ${ }^{5}$ The WHO prescribing indicators were calculated using the following formulae. ${ }^{4}$

\section{Indicator 1}

This is the average number of drugs per prescription, which helps to measure the degree of polypharmacy. It was obtained by dividing the total number of drugs prescribed by the number of prescriptions studied.

\section{Indicator 2}

It displays the percentage of drugs prescribed by generic name. This is to calculate the tendency to prescribe by generic name. It was achieved by dividing the number of drugs prescribed by generic name by the total number of drugs prescribed, multiplied by 100 .

\section{Indicator 3}

It shows the percentage of prescriptions with an antibiotic prescribed. This helps to evaluate the extent of misuse of antibiotic. It was calculated by dividing the number of prescriptions in which antibiotics were prescribed by the total number of prescriptions surveyed, multiplied by 100 .

\section{Indicator 4}

This was to determine the percentage of prescriptions with an injection prescribed. It measured the level of overuse of injectables. It was obtained by dividing the number of prescriptions in which injections were prescribed by the total number of prescriptions studied, multiplied by 100 .

\section{Indicator 5}

This determined percentage of drugs that were prescribed from the Essential Drug List. It measured the degree to which prescribing practices conformed with National List of Essential Medicine of India. It was calculated by dividing the number of drugs prescribed which are listed on the NLEM by the total number of drugs prescribed multiplied by 100 .

\section{Operational definitions}

Generic name: NLEM 2015, WHO $18^{\text {th }}$ list of essential medicines, CIMS were used as a basis to confirm the generic name of a drug.

Antibiotics: Drugs such as antibacterial, anti-infective dermatological drugs, and anti-infective ophthalmological agents, from WHO $18^{\text {th }}$ List of Essential Medicines, were considered as antibiotics in this study.

Combination of drugs that are prescribed for a given health condition was counted as one.

Polypharmacy: concurrent use of two or more drugs for a given patient.

\section{RESULTS}

600 prescriptions written by medical practitioners, obtained from the patients, from various private pharmacies in the state of Goa, were analysed prospectively from March to April 2016.

Table 1: WHO prescribing indicators.

\begin{tabular}{|llll|}
\hline $\begin{array}{l}\text { WHO prescribing } \\
\text { indicators }\end{array}$ & $\begin{array}{l}\text { Number } \\
\text { of drugs }\end{array}$ & Results & $\begin{array}{l}\text { Ideal } \\
\text { values }\end{array}$ \\
\hline $\begin{array}{l}\text { Average number of } \\
\text { drugs per prescription }\end{array}$ & 1903 & 3.17 & $1.6-1.8$ \\
\hline $\begin{array}{l}\text { Percentage of drugs } \\
\text { prescribed by generic } \\
\text { name }\end{array}$ & 11 & $0.58 \%$ & $100 \%$ \\
\hline $\begin{array}{l}\text { Percentage of } \\
\text { antibiotics prescribed } \\
\text { per prescription }\end{array}$ & 119 & $19.83 \%$ & $\begin{array}{l}20- \\
26.8 \%\end{array}$ \\
\hline $\begin{array}{l}\text { Percentage of } \\
\text { injections prescribed } \\
\text { per prescription }\end{array}$ & 23 & $3.8 \%$ & $13.4-$ \\
\hline $\begin{array}{l}\text { Percentage of drugs } \\
\text { prescribed from }\end{array}$ & 567 & $29.1 \%$ \\
NLEM 2015
\end{tabular}

Out of the 1900 drugs prescribed, average number of drugs per prescription was 3.17. Total number of drugs prescribed by generic name was $11(0.58 \%)$. An antibiotic 
was prescribed in 119 patients (19.83\%). An injection was prescribed in 23 patients (3.8\%). 567 drugs prescribed were from the National List of Essential Medicines (29.8\%) (Table 1).

Out of the 1903 drugs prescribed in this study, the percentages of drugs prescribed by oral, topical and parenteral route were $88 \%, 2 \%$ and $10 \%$ respectively (Figure 1).

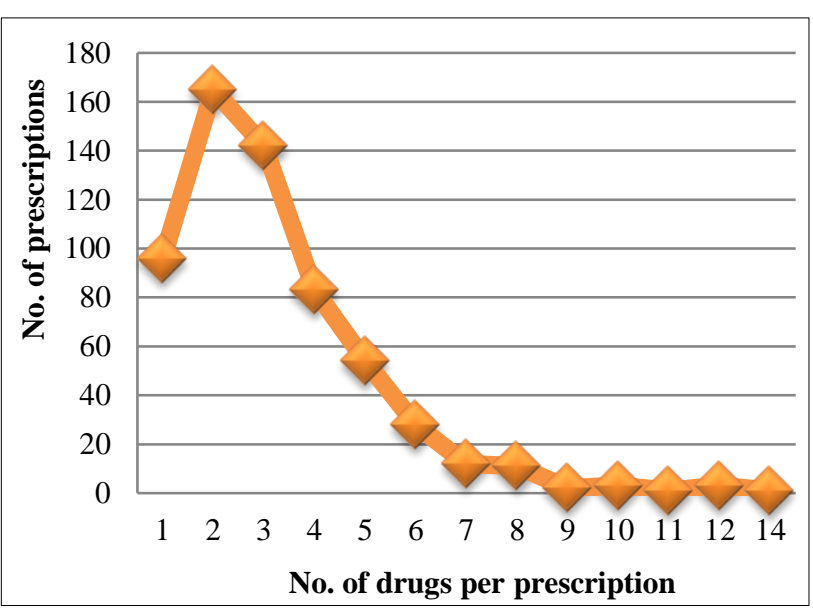

Figure 1: Number of drugs per prescriptions.

Maximum number of prescriptions (165) contained 2 drugs. The number of drugs prescribed per prescription varied from 1 to 14 (Figure 2).

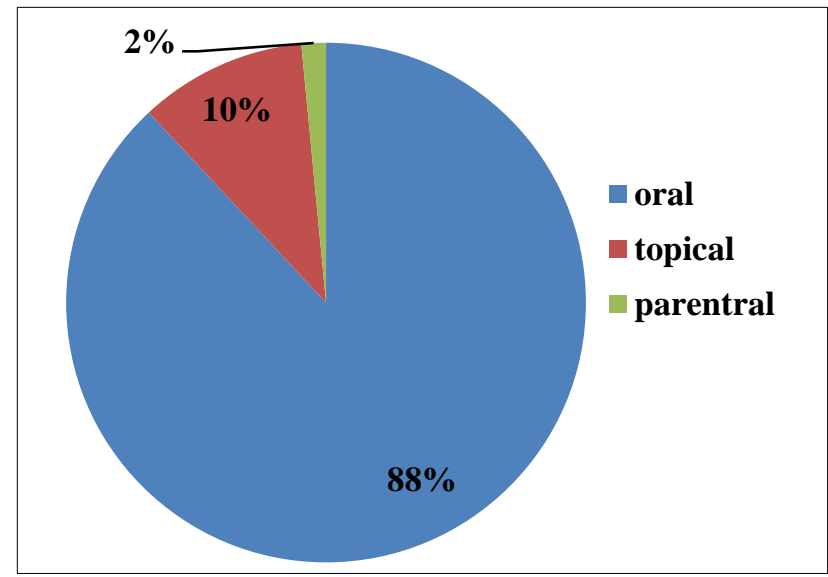

Figure 2: Percentage of drugs prescribed by specific routes.

Among all the drugs prescribed, antimicrobials were most commonly prescribed $(\mathrm{n}=317,17 \%)$ followed by vitamins/minerals/antioxidants $\quad(\mathrm{n}=307,16 \%)$ and cardiovascular drugs $(n=297,15.6 \%)$. Drugs other than antibiotics for genitourinary system were prescribed the least $(\mathrm{n}=13,1 \%)$ (Table 2$)$.

Among antimicrobials, amoxicillin and clavulanic acid fixed dose combination was the most commonly prescribed followed by cefixime, azithromycin, doxycycline, ciprofloxacin (Figure 3).

Table 2: Category-wise prescribing frequency.

\begin{tabular}{|l|l|l|}
\hline Drug Categories & $\begin{array}{l}\text { Number } \\
\text { of drugs } \\
\text { prescribed } \\
(\mathbf{1 9 0 3 )}\end{array}$ & $\begin{array}{l}\text { \% of } \\
\text { drugs } \\
\text { prescribed }\end{array}$ \\
\hline Antimicrobials & 317 & $17 \%$ \\
\hline vitamins/minerals/antioxidants & 307 & $16 \%$ \\
\hline Cardiovascular drugs & 297 & $15.6 \%$ \\
\hline CNS drugs & 188 & $10 \%$ \\
\hline Gastrointestinal drugs & 177 & $9 \%$ \\
\hline Analgesics & 170 & $9 \%$ \\
\hline $\begin{array}{l}\text { Respiratory drugs and } \\
\text { antihistaminics }\end{array}$ & 156 & $8 \%$ \\
\hline Endocrine & 142 & $7 \%$ \\
\hline Musculoskeletal drugs & 44 & $2 \%$ \\
\hline Steroids & 40 & $2 \%$ \\
\hline $\begin{array}{l}\text { Genitourinary other than } \\
\text { antibiotics }\end{array}$ & 13 & $1 \%$ \\
\hline Others & 60 & $3 \%$ \\
\hline
\end{tabular}

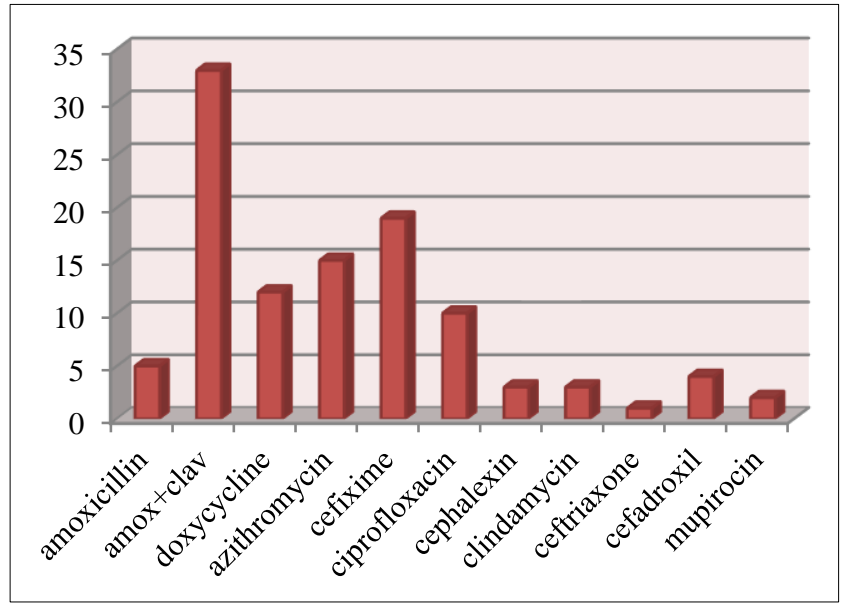

Figure 3: Commonly prescribed antibiotics.

\section{DISCUSSION}

This study revealed that the average number of drugs prescribed per encounter was 3.17, with a maximum of 14 drugs prescribed per prescription. This value is higher than the ideal (1.6-1.8) values. However, this study value was found to be lower when compared to similar studies carried out in Chennai, Tamil Nadu (4.38), Shimoga, Karnataka (5.3), Chandigarh, Punjab (3.6), Maharashtra (3.62), North India (4.02) and higher in the areas of Bhopal, Madhya Pradesh (2.35), Jalna, Maharashtra (2.82). ${ }^{6-12}$

This study demonstrated that prescribing by generic name was at a disappointing level of $0.58 \%$, when the ideal value was $100 \%$. Similar domestic research findings also showed unsatisfactory results. ${ }^{6-8,12}$ A study in North India revealed that not even a single drug was prescribed by 
generic name. ${ }^{10}$ However a few other studies showed promising results. ${ }^{11,13,14}$ Similar studies in Pakistan (83.1\%), Nepal (84\%), Northern Ethiopia (93.3\%), Brazil $(86.1 \%)$, China $(96.12 \%)$ noted better results. ${ }^{15-19}$ The WHO endorses prescribing medication by its generic name. It enables easy identification of medication and better communication between health care providers. ${ }^{20}$

In this study, the percentage of antibiotics prescribed per prescription was $19.83 \%$. According to WHO, in developing countries where infectious diseases are more prevalent, $15-25 \%$ of prescriptions with antibiotics is expected. ${ }^{4}$ Cautious use of antibiotics is warranted in the present era, were antibiotic resistance have become rampant.

Only $3.8 \%$ of prescriptions prescribed were of injectables. This is a good sign, as one of the key factors for the irrational use of medicines is the injudicious use of injections, when oral formulations would have been more appropriate. $^{2}$

In this study, only $29.8 \%$ medicines were prescribed from the National Essential List of Medicine (100\% being the ideal value). In contrast to the present study, medicines prescribed from the National Essential List of Medicine were higher in the states of Karnataka (90.18\%), Maharashtra (81.6\%), Madhya Pradesh (73.54\%) in India, and countries like Ethiopia (96.6\%), Sudan (72.83\%), Nigeria (94\%), Sri Lanka, Brazil (80\%), Pakistan $(98.8 \%) .^{7,9,11,21-26}$ Adopting the NELM in clinical practice promotes rational, safe and cost effective utilization of medicines. ${ }^{27}$

\section{CONCLUSION}

The medical practitioners in Goa did not adhere to all the prescribing indicators formulated by WHO. This study revealed the irrational practice of polypharmacy, which is an important risk factor for drug-drug interactions and adverse drug reactions. This study also showed the failure of medical practitioners to prescribe drugs by their generic names and from the national essential list of medicines. This study finding, will contribute to national and international literature, which can be used by policymakers to implement policies to improve rational prescribing pattern. Problem-based pharmacotherapy training in undergraduate curricula, continued medical education for medical practitioners, establishment of drug information centers and drug bulletins, public awareness about medicines, appropriate and enforced regulations by competent authorities are some of the core policies suggested by WHO to promote rational use of medicines. ${ }^{2}$

\section{Funding: No funding sources}

Conflict of interest: None declared

Ethical approval: The study was approved by the Institutional Ethics Committee of Goa Medical College, Bambolim-Goa, India

\section{REFERENCES}

1. The rational use of drugs, Report of the Conference of Experts, Nairobi, November; 1985:25-29. Available at: http://apps.who.int/medicinedocs/documents/s17054e /s17054e.pdf. Accessed 20 May 2017.

2. WHO Policy Perspectives on Medicines - Promoting rational use of medicines: core components. September 2002. World Health Organization Geneva. Available at: http://apps.who.int/medicinedocs/pdf/h3011e/h3011e. pdf. Accessed 20 May 2017.

3. Tripathy KD. Essentials of Medical Pharmacology. 7thEdition. New Delhi: Jaypee Brothers Medical Publishers (P) Ltd.; 2013:4.

4. How to investigate drug use in health facilities: selected drug use indicators, WHO; 1993:1-92. Available http://apps.who.int/medicinedocs/en/d/Js2289e. Accessed 20 may 2017.

5. Isah AO, Ross-Degnan D, Quick J, Laing R, Mabadeje AFB, The development of standard values for the WHO drug use prescribing indicators. Available at: http://archives.who.int/icium/icium1997/posters/1a2_ txt.html. Accessed 20 May 2017.

6. Geetha P, Vijayalakshmi P, Tilak S, Maheswaran A, Narayanan N. Prescription analysis to evaluate the rational use of drugs by using who health care indicators. Int. J. Multidiscip. Res. Dev. 2015 May;2(5):358-60.

7. Prasad SN, Jagadeesh K, Revankar S. Study of Rationality Of Prescriptions \& Analysis Of Drugs Prescribed Among In-Patients Of Mcgann Teaching Hospital, S.I.M.S, Shimoga, Karnataka, India. IOSRJDMS. 2014 July;13(7):30-5.

8. Mittal N, Mittal R, Singh I, Shafiq N, Malhotra S. Drug Utilisation Research in a Tertiary Care Center: Recommendations for Improving Hospital Drug Dispensing Policies. Indian $\mathbf{J}$ Pharm Sci. 2014;76(4):308-14.

9. Lalan BK, Hiray RS, Ghongane BB. Drug prescription pattern of outpatients in a tertiary care teaching hospital in Maharashtra. Int J Pharm Bio Sci. 2012 July;3(3):225-9.

10. Ahsan M, Shaifali I, Mallick AK, Singh HK, Verma S, Shekhar A. Prescription auditing based on World Health Organization (WHO) prescribing indicators in a teaching hospital in North India. Int J Med Res Rev. 2016;4(10):1847-52.

11. Gupta R, Marko JL. Drug prescription pattern of outpatients in a tertiary care teaching hospital in central India. Iint. J. Bioassays, 2014;3(12):3566-8.

12. Khan IN, Chandrakapure AR, Mateenuddin M, Arif S, Giri S, Faheem M. Prescription pattern in OPD hospital in a rural area of Jalna Dist, Maharashtra, India, Med Pulse -International Medical Journal. 2014 April;1(4):165-7.

13. Gangopadhyay T, Mandal A, Mandal S, Basu B, Maiti $\mathrm{T}$, Das A, et al. Drug utilization study from a 
government sponsored pharmacy in a tertiary care teaching hospital of rural West Bengal: A crosssectional study. Int J Health Allied Sci. 2016;5(3):13842.

14. Pathak A, Gupta VK, Maurya A, Kumar A, Singh A. Assessment of drug prescribing pattern using WHO indicators inhospitalized patients at a tertiary care teaching hospital in rural area of India. Int J Basic Clin Pharmacol. 2016 Jun;5(3):651-5.

15. Atif M, Azeem M, Sarwar MR, Shahid S, Javaid S, Ikram $\mathrm{H}$, et al. WHO/INRUD prescribing indicators and prescribing trends of antibiotics in the Accident and Emergency Department of Bahawal Victoria Hospital, Pakistan. Springer Plus. 2016;5:1928.

16. Sapkota S, Pudasaini N, Singh C, Sagar GC. Drug prescribing pattern and prescription error in elderly: a retrospective study of inpatient record, Asian J Pharm Clin Res. 2011;4(3):129-32.

17. Demeke B, Molla F, Assen A, Melkam W, Abrha S, Masresha B, et al. Evaluation of drugs utilization pattern using who prescribing indicators in ayder referral hospital, Northern Ethiopia. International Journal of Pharma Sciences and Research. 2015 Feb;6(2):343-7.

18. Ferreira MB, Heineck I, Flores LM, Camargo AL, Dal Pizzol TD, Torres IL, et al. Rational use of medicines: prescribing indicators at different levels of health care. Brazilian Journal of Pharmaceutical Sciences. 2013 Jun;49(2):329-40.

19. Wang H, Li N, Zhu H, Xu S, Lu H, Feng Z, et al. Prescription Pattern and Its Influencing Factors in Chinese County Hospitals: A Retrospective CrossSectional Study. Plos One. 2013 May;8(5):e63225.

20. Guidance on international nonproprietary names (INN) for pharmaceutical substances, WHO; 1997. Available at: www.who.int/medicines/services/inn/innguidance/en. Accessed 20 May 2017.
21. Desalegn AA. Assessment of drug use pattern using WHO prescribing indicators at Hawassa University teaching and referral hospital, South Ethiopia: a crosssectional study. BMC Health Services Research. 2013;13:170.

22. Mahmoud RK, Kheder SI, Ali HM. Prescribing rationality in Khartoum state, Sudan: An update. Sudan Med Monit. 2014 April;9(2):61-6.

23. Tamuno I, Fadare JO. Drug Prescription Pattern in a Nigerian Tertiary Hospital. Trop J Pharm Res. 2012 February;11(1):146-52.

24. Menik HL, Isuru AI, Sewwandi S. A survey: Precepts and practices in drug use indicators at Government Healthcare Facilities: A Hospital-based prospective analysis. J Pharm Bioallied Sci 2011 JanMar;3(1):165-9.

25. Vooss AT, Diefenthaeler HS. Evaluation of prescription indicators established by the WHO in Getúlio Vargas- RS. Brazilian Journal of Pharmaceutical Sciences. 2011 April/June;47(2):38590.

26. Atif M, Sarwar MR, Azeem M, Umer D, Rauf A, Rasool A, et al. Assessment of WHO/INRUD core drug use indicators in two tertiary care hospitals of Bahawalpur, Punjab, Pakistan. Journal of Pharmaceutical Policy and Practice. 2016;9:27.

27. Kar SS, Pradhan HS, Mohanta GP. Concept of Essential Medicines and Rational Use in Public Health. Indian J Community Med. 2010 Jan;35(1):103.

Cite this article as: Upendra $\mathrm{G}$, Bhounsule SA. Evaluation of prescribing patterns of medical practitioners in the state of Goa, India. Int J Basic Clin Pharmacol 2017;6:2214-8. 